Original Research Paper

\title{
Comprehensive Assessment of Spatial Distribution of Road- Network Vulnerability in South Asia
}

\author{
${ }^{1,2,3}$ Pan Yuqi, 1,3 Jiang Penghui, ${ }^{1,3}$ Li Manchun and ${ }^{1,3}$ Chen Dengshuai \\ ${ }^{1}$ Jiangsu Provincial Key Laboratory of Geographic Information Science and Technology, \\ Nanjing University, Nanjing, Jiangsu, China \\ ${ }^{2}$ Provincial Geomatics Centre of Jiangsu, Nanjing, Jiangsu, China \\ ${ }^{3}$ School of Geographic and Oceanographic Sciences, Nanjing University, Nanjing, Jiangsu, China
}

\section{Article history}

Received: 04-08-2021

Revised: 30-09-2021

Accepted: 18-11-2021

Corresponding Author:

Penghui Jiang

Jiangsu Provincial Key

Laboratory of Geographic

Information Science and

Technology, Nanjing

University, Nanjing, Jiangsu,

China

Email: jiangph1986@nju.edu.cn

\begin{abstract}
Unexpected phenomena-natural disasters, accidents and wars-can disrupt regional traffic systems because of the incapacities of road networks to sustain inflicted impacts. Therefore, the assessment of road-network vulnerability becomes integral to traffic-safety-maintenance and accidentprevention procedures. This study demonstrates the development of a comprehensive network system based on suggested improvements in node extraction, road construction and network attribution. An indicator system for assessing road-network vulnerability was established to be compatible with the South Asian environment and its geographical characteristics by integrating multisource data-topography, geology and meteorological and geopolitical environments. Employing the GIS-based spatial-analysis technique, a vulnerability-assessment model for South Asian road networks was constructed and spatial distributions of vulnerability characteristics were examined under extreme natural and human-influenced environments. The results demonstrate that the road-network-vulnerability distribution in India follows a decreasing trend outwards from the central part of the country. The highest road-network-vulnerability levels of 7 and 8 were observed in the central and northern parts of the Deccan plateau as well as the western coastal and northern mountainous regions. The northernmost part of Pakistan is characterized by road-vulnerability levels in the range of 9-10. Owing to the heavy influence of India-Pakistan conflicts and terror attacks, road networks in proximity to the India-Pakistan border are assigned the highest vulnerability level of 10 . The results of this study demonstrate that changes in and the impact of, the geopolitical environment are primary factors influencing road-network vulnerability in South Asia.
\end{abstract}

Keywords: South Asia, Road-Network Construction, Spatial Analysis, Analytic Hierarchy Process (AHP), Road-Network-Vulnerability Assessment Model

\section{Introduction}

Road-network systems corresponded to a collection of links that connect different geospatial entities together. The optimum maintenance of road networks is a fundamental requirement in the pursuit of sustainable economic and social development (Gedik et al., 2014; Wang et al., 2020). However, road-network systems may become subject to temporary failures caused by road degradation, occurrence of natural disasters and human activities. Such disruptions invariably cause a significant reduction in transportation efficiency, which in turn negatively affect the daily life of concerned individuals (Miller et al., 2003). The disruption of transportation networks can be caused by a variety of factors ranging from abrupt events, such as natural and human-inflicted disasters, to recurring activities, such as high average daily temperatures and rainfall. Given the high criticality of transportation networks for the functioning of modern society and its susceptibility to interference from natural and human elements, the evaluation of the vulnerability of transportation networks may prove to be of a great utility in applications such as the development of traffic-accident-warning systems, emergency-response activities and disaster prevention. 
The key to assess the road-network vulnerability lies in the selection, quantification and construction of an indicator system incorporating the internal and external factors that influence the said vulnerability of road networks. Such indicator systems facilitate the evaluation of the potential vulnerability of road networks located in complex geographical environments. Different studies have proposed different definitions of road-network vulnerability based on their distinctive research priorities and methods employed. Currently, road-network vulnerability can roughly be defined based on two situations, as described below.

In the first situation, road-network vulnerability can be associated with the consequences of partial road-network failure. In this context, the vulnerability of a road network is in no way concerned with its failure probability. For example, Sohn (2006) and Scott et al. (2006) proposed the assessment of road-network vulnerability using road-network performance indicators. Chen et al. (2012) proposed an approach based on an "impact area" vulnerability analysis to evaluate the consequences of link closure within the impact area instead of the entire network. Berdica and Mattsson (2007) investigated the vulnerability of road networks by analyzing how interruptions caused on different critical links affect the road network in Stockholm whilst also analyzing the importance of the said links with respect to each other. Kim and Yeo (2016) compared the behaviors of the Macroscopic Fundamental Diagram (MFD) under normal and event conditions, thereby developing a measure referred to as the MFD-based Vulnerability Index (MVI) for evaluating the vulnerability of urban road networks. Tang and Huang (2019) Assessed seismic vulnerability of urban road networks by a Bayesian network approach.

In the second situation, the vulnerability of road networks is closely related to the associated risk. That is, the vulnerability of road networks can be represented by a risk value, which can be calculated by considering both the aftermath and the probability of road failure. For example, Jenelius and Mattsson (2012) analyzed the vulnerability of road networks based on the probability of disruptive events as well as their consequence at a specific location and time. Bell et al. (2008) presented a gametheory-inspired approach for the analysis of road-network vulnerability by considering probabilities of events that affect the use of road networks. Miller et al. (2003) considered the vulnerability, reliability and risks associated with a road network as three closely related concepts, Lu et al. (2021) proposes an accessibility approach addressing attributes of road infrastructure to measure road network vulnerability.

Based on the study performed by Murray et al. (2008), there currently exists four methods to evaluate the vulnerability of road networks. The first method performs scenario-specific assessment of road-network vulnerability by evaluating the potential ramifications of a specific disruption scenario. The second method provides a strategy-specific assessment that analyzes losses in road-network facilities that may occur in the event of external attacks. This approach has proven to be effective with regard to assess the vulnerability of different network configurations to specific scenarios. An example of this method involves the assessment of road-network vulnerability via the use of graphic theories. The third method assesses road-network vulnerability via simulation analysis, wherein the most feasible scenario associated with a particular practical condition is reconstructed via simulation. The fourth method performs a mathematical-modeling-based assessment that seeks to identify vulnerable sections of a road network by constructing models or deducing expressions.

Although a large amount of literature has been published in this regard, certain aspects concerning roadnetwork-vulnerability assessment remain unexplored. First, only very few extant studies have attempted to explore the impact of extreme geopolitical environments on the vulnerability of regional road networks. As rightly pointed out by Singh et al. (2018), most investigations on the vulnerability assessment of road networks exclusively consider topographic properties along with the supply and demand aspects of the transportation system. Second, most systems developed for the assessment of road-network vulnerability are established basing on a single objective, sans a comprehensive consideration of all important factors including natural and human-inflicted ones. For example, the study reported by Quium and Hoque (2002) evaluated the connectivity of road networks based on the use of two connectivity indices- $\gamma$ and $\alpha$-as indicators to assess road-network vulnerability under a single evaluation criterion-i.e., susceptibility to flooding. Kermanshah and Derrible (2016) developed a geographical multicriteria vulnerability-assessment method to quantify the impacts of extreme earthquakes on road networks. Grubesic et al. (2008) proposed the use of global and local indicators for assessing the vulnerability of road networks based on graph-theoretic measures. D'Este (2001) analyzed roadnetwork vulnerability using a single generalized travelcost indicator based on the ease of reaching the target location. Liu et al. (2021) Measured the dynamic evolution of road network vulnerability to floods of Wuhan, China. Reggiani et al. (2015) adapted the concepts of graph theory and proposed two means for the assessment of road-network vulnerability by using either a single topological property index or separate supply and demand indicators for a single transportation system. Analyzing the vulnerability of road networks subjected by multiple interfering impacts is a complex problem. In addition, the magnitude, impact and predictability of events that influence road-network vulnerability vary substantially, thereby making the determination of their corresponding probabilities and uncertainties extremely 
complicated. It is, therefore, necessary to quantify the potential vulnerability of a road network using a reliable and effective vulnerability-impact factor. South Asian countries exhibit complex geophysical relationships, poor economic development and complex natural environment. All these factors significantly increase the vulnerability of local road networks in South Asia. With the progression of the belt and road initiative, the identification of the spatial distribution of potential road-network vulnerability in South Asian countries has assumed extreme importance, especially from the perspective of sustainability.

In the view of the road safety is uncertain and definitely not the same for all regions of the world (Wegman, 2017). And the common consensus recognizes that traffic accidents are the results of three different factor types, namely, human factors, vehicle factors and external factors (including road conditions) (Soehodho, 2017). With these considerations, our study presents a method to explore and analyze spatial-distribution characteristics of road network-vulnerability by combining the effects of the extreme natural environment of South Asia with local human-induced political and educational factors. The proposed method covers several aspects such as data processing, road-network construction, index extraction and quantitative modeling to facilitate qualitative, quantitative and position-based assessment of potential road-network vulnerabilities. In addition, this study also constructs an index system suitable for the environment of South Asia. The findings of this study provide a new method for the evaluation of local traffic conditions whilst facilitating access to predictive guidance by way of traffic-accident warnings, emergency response and disaster-prevention planning.

\section{Overview of Local Region and Sources of Relevant} Data

\section{Overview of Local Region}

South Asia is a vast region located between the southcentral and western regions of the Himalayas and the northern part of the Indian Ocean (Fig. 1). The geographical coordinates (latitudes and longitudes) of this region lie in the range of $0-37^{\circ} \mathrm{E}$ and $59-98^{\circ} \mathrm{N}$, respectively. The region neighbors the Bay of Bengal on its east, Arabian Sea on the west and China in the north. In addition, the region is also bordered by Southeast Asia to its east and West Asia along the northwest direction. South Asia comprises seven countries, including Nepal, Bhutan, India, Pakistan, Bangladesh, Sri Lanka and Maldives and occupies a land-mass area of roughly $4.3 \times 106 \mathrm{~km}^{2}$.

The region comprises three types of terrain. To its north lies the Himalayan mountain range with an average elevation exceeding $6000 \mathrm{~m}$. It separates South Asia from the rest of the Asian continent. The central part of South Asia comprises a large alluvial plain formed by deposition of sediments from the Indus, Ganga and Brahmaputra rivers. The southern part of the region comprises the Deccan plateau surrounded by coastal plains on either side. Diving the Deccan plateau from coastal plains are the Eastern and Western Ghats.

In view of the above-mentioned geological factors, South Asia can be considered to be relatively isolated from the geographical perspective. In fact, the region is also, at times, referred to as the "South Asian subcontinent." Most of this region experiences the tropical monsoon climate that is characterized by three annual seasons-summer (March-May), monsoon (June-October) and winter (November-February). Temperatures in this region remain high throughout the year with a diverse range of precipitation levels that vary from one place to another. The southwestern part of the subcontinent comprises a monsoon windward slope with abundant precipitation. In fact, it ranks amongst regions with the highest precipitation in the world (e.g., Lapungzi in India). In contrast, very little precipitation is observed in the northwest part of the subcontinent. Owing to political instability and religious conflicts, certain parts of the subcontinent experience a high occurrence of terror attacks. As depicted in the global map of accumulated terror-attack frequency between 1970 and 2017 (Fig. 1; blue and orange colors represent low and high terror-attack frequencies, respectively), such attacks occur frequently in the northwest part of the subcontinent. The rise of international terrorist forces, such as the ISIS and Al Qaeda, along with the prolonged dispute along the India-Pakistan border continue to strain the local political situation in South Asia.

Most South Asian countries, in general, have poor traffic infrastructure. Compared to other regions in the world, both the length and density of highways is relatively low in the entire subcontinent and a reasonable and efficient road-network structure has not yet been developed in South Asian countries. Furthermore, there exists a lack in synergy between different transportation routes and modes. The economic, density and range effects associated with transport-network development can be considered nonexistent in this part of the world. Simultaneously, limited knowledge of infrastructure planning and lack of assessment of the potential vulnerability of road networks have led to poor maintenance of road networks. Thus, local road networks in this region fail to facilitate positive interaction between transportation, industrial layout and economic development.

\section{Data Sources}

The data used in this study included remote-sensing data, basic geographical information and other spatial data, as summarized in Table 1. 
Table 1: Sources of the data used in this study

\begin{tabular}{|c|c|c|c|}
\hline Type & Name & Format & Source \\
\hline \multirow[t]{2}{*}{ Remote sensing } & $\begin{array}{l}\text { Google unbiased satellite remote } \\
\text { sensing image products }\end{array}$ & Raster & $\begin{array}{l}\text { Landsat Copernicus Remote } \\
\text { Sensing Image Data }\end{array}$ \\
\hline & NPP-VIIRS (Visible infrared Imaging Radiometer) & Raster & National Oceanic and Atmospheric \\
\hline \multirow[t]{5}{*}{ Basic geographic } & $\begin{array}{l}\text { Night light remote sensing data products } \\
\text { Digital Elevation Model }\end{array}$ & Raster & $\begin{array}{l}\text { Administration (NOAA) } \\
\text { National Aeronautics and Space } \\
\text { Administration (NASA) }\end{array}$ \\
\hline & Administrative division data & Vector & Global Administrative Areas (GADM) \\
\hline & Provincial capital data & Vector & Open Street Map (OSM) \\
\hline & Port data & Vector & Marine Traffic \\
\hline & Network data & Vector & Open Street Map and Map box \\
\hline \multirow[t]{4}{*}{ Other spatial } & Seismic point data & Vector & United States Geological Survey (USGS) \\
\hline & Terrorist attacks Point data & Vector & Global Terrorism Database (GTD) \\
\hline & Precipitation data & Raster & Climate hazards group infrared precipitation \\
\hline & Temperature data & Raster & with station data (CHIRPS) NOAA \\
\hline
\end{tabular}

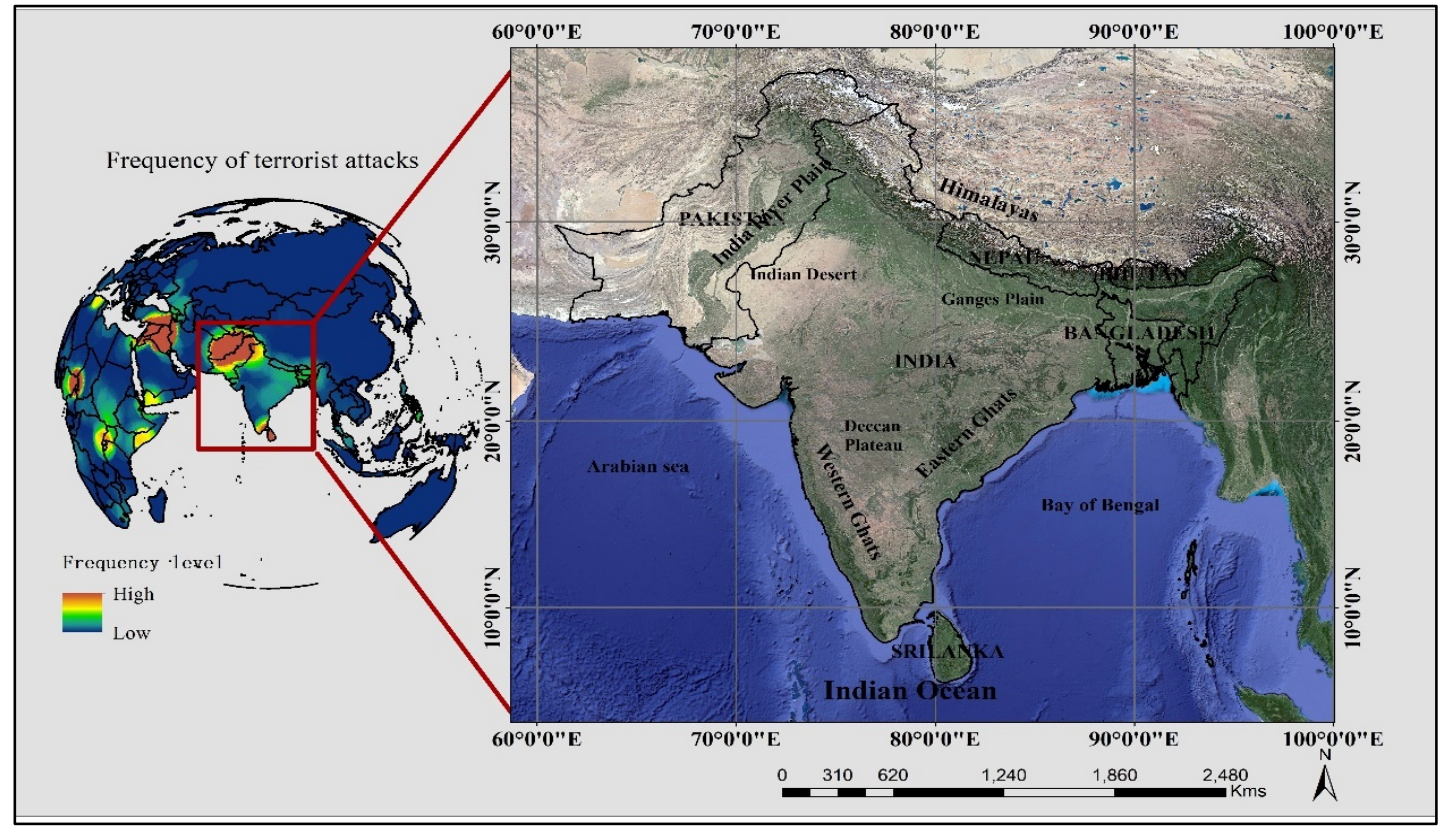

Fig. 1: Regional map of South Asia depicting frequency of occurrence of terror attacks

\section{Research Methods}

After preprocessing, the data were used in subsequent calculations. Figure 2 depicts a flowchart of the methodology followed during the development of the proposed technique for road-network-vulnerability assessment.

\section{Road-network Construction}

The extraction of major road networks in South Asia constituted the basic groundwork performed in this study with regard to the vulnerability assessment of the said road networks. To accomplish this task, a primitive abstraction method was employed to transform intersections and roads to nodes and edges, respectively, thereby simplifying road networks to graphs comprising a number of points and lines connecting these points to one another. In addition, geographical information concerning the said intersections and roads was assigned to corresponding nodes and edges as attribute values. In this way, complex real-world road networks were converted into a simple network structure amenable to spatial analysis and subsequent processing.

Subsequent to the above road-network simplification, five types of point data corresponding to the harbor, provincial capital, capital, port and major cities were extracted in the form of road-network nodes. Subsequently, the road network connecting these nodes was extracted based on data obtained from different tools-Open Street Map (OSM), Mapbox and Natural Earth. Attributes concerning the road network were further improved using network data. Detailed information in this regard has been included in Appendix 1. Figure 3 depicts the road network finalized for use in this study. 


\section{Development of Indicator System}

\section{Indicator Selection}

The development of the indicator system to facilitate road-network-vulnerability assessment required accurate indicator selection and quantification. These processes aimed at identifying potential factors affecting roadnetwork security followed by the quantification of the corresponding vulnerability. Therefore, appropriate indicator selection constitutes a critical step towards ensuring the accurate assessment of road-network vulnerability. The road-network system in South Asia can be classified as being, both, complex and fragile, because it is affected by multiple factors-the internal physical structure of the road network, the external natural environment and politics factors. Indicators considered to use in this study must, therefore, fully reflect potential factors influencing the vulnerability of road networks. Further, they must be feasible with regard to the collection of spatial data associated with them. In general, the construction of the indicator system must abide by the principles of being scientific, comprehensive, systematic, concise and operable. Fig. 4 depicts details concerning the indicator-selection process.

\section{Indicator Quantification}

Prior to the construction of a comprehensive evaluation model, all vulnerability-impact indicators must be quantified and integrated into road-network properties. Hence, the value of each indicator can be substituted into the model developed in this study to facilitate the evaluation of road-network vulnerability in South Asia. Based on the impact indicators selected in this study, the corresponding basic data were obtained and subsequently preprocessed using GIS spatial-analysis techniques (Fig. 5). Prior to performing the resampling operation during the said analysis, raster data must be quantified (i.e., indicator quantification process) in accordance with different factors such as the extent, mode and scale of the vulnerability of concerned road networks. To this end, a quantitative value that reflects the degree of road-network vulnerability can be obtained based on raw-data values. The details concerning the quantification method have been included in Appendix 2.

\section{Construction of Comprehensive-Assessment Model}

\section{Determination of Indicator Weights}

Considering the impact of all previously mentioned factors on the transportation environment in South Asia, a vulnerability assessment system was developed, as summarized in Table 2. Based on the finalized indicator system described in the last subsection, weights concerning each assessment indicator were determined using the model based on the Analytic Hierarchy Process (AHP), which is a multiobjective decision-analysis process that combines the qualitative and quantitative approaches. By breaking a complex problem down into smaller elements with multiple levels, comparing the level of importance between any two indicators and calculating the maximum eigenvalues and corresponding eigenvectors based on the said comparison, weights corresponding to each selected indicator can be determined. Table 2 lists the values of composite weights assigned to elements in the bottom layer with respect to the top layer and those calculated based on weight values assigned to indicators within each layer. The detailed analysis principle has been described in Appendix 3 .

\section{Vulnerability Assessment of Road Networks in South Asia}

To assess the vulnerability of road networks in South Asia, factors influencing the said vulnerability were assigned to road-network attributes and subsequently used to perform corresponding calculations based on the proposed model. The relevant analysis can be described as follows. Influencing indicators were first identified followed by the determination of their associated weight values. Subsequently, a distribution map of road-network vulnerability caused under the influence of the external environment was generated based on assigned weight values. Letters I and $\mathrm{L}$ were used to denote the raster image concerning the distribution of road-network vulnerability caused by an external environment and South Asian road-network layer, respectively. Subsequently, the raster image I was converted to a polygon layer $\mathrm{P}$ by converting the pixel values of I to properties concerning polygon $\mathrm{P}$, which represents the external vulnerability of concerned road networks. Next, spatial-recognition analysis was performed on the external-environment-vulnerability layer and self-vulnerability indicator values of the concerned road network via use of the GIS spatialsuperposition technique. Layers $\mathrm{P}$ and $\mathrm{L}$ were used as the identification and input layers, respectively. Layer L was then segmented in accordance with the polygon-layer P, implemented in combination with vulnerability attributes and it was ultimately assigned a corresponding attribute value. Based on road-network data, all indicator-vulnerability values were substituted into the evaluation model, thereby yielding a comprehensive result pertaining road-network vulnerability.

Table 2: Composite results of index weight values

\begin{tabular}{ll}
\hline Evaluation index & Weights \\
\hline Vulnerability of topographic & 0.0491 \\
Vulnerability of earthquake & 0.0655 \\
Vulnerability of traffic speed & 0.0327 \\
Vulnerability of precipitation & 0.1487 \\
Vulnerability of high temperature & 0.1487 \\
Vulnerability of terrorist attacks & 0.1617 \\
Vulnerability of India-Pakistan conflicts & 0.3773 \\
\hline
\end{tabular}


Pan Yuqi et al. / American Journal of Environmental Sciences 2021, 17 (6): 108.124 DOI: 10.3844/ajessp.2021.108.124

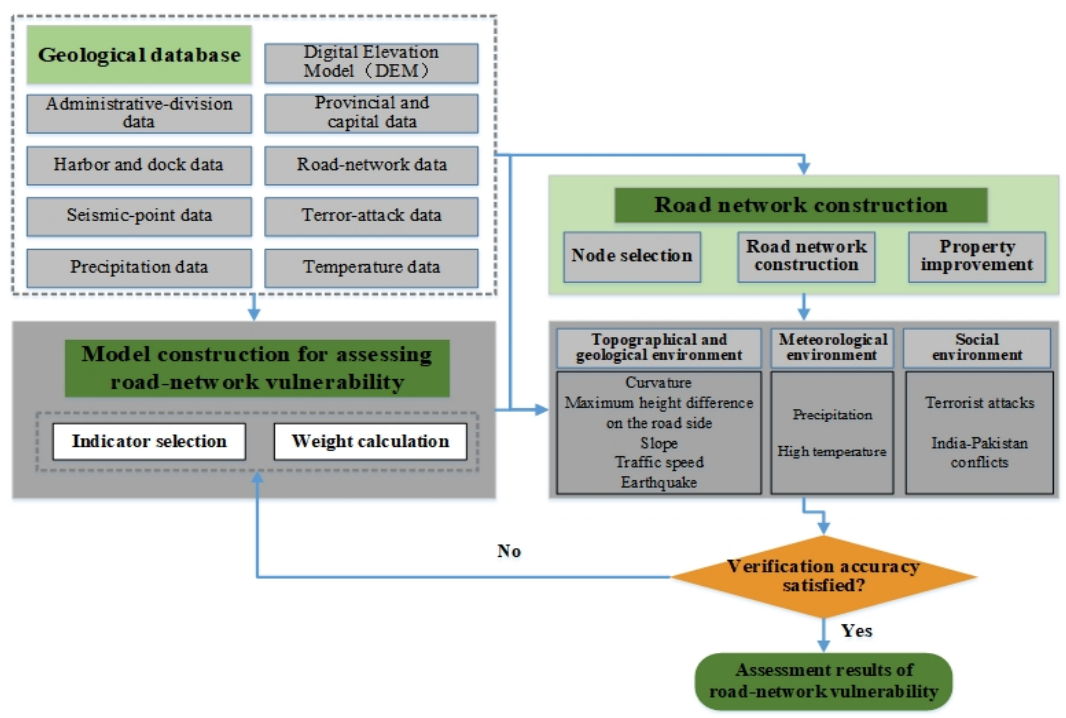

Fig. 2: Flowchart for road-network-vulnerability assessment

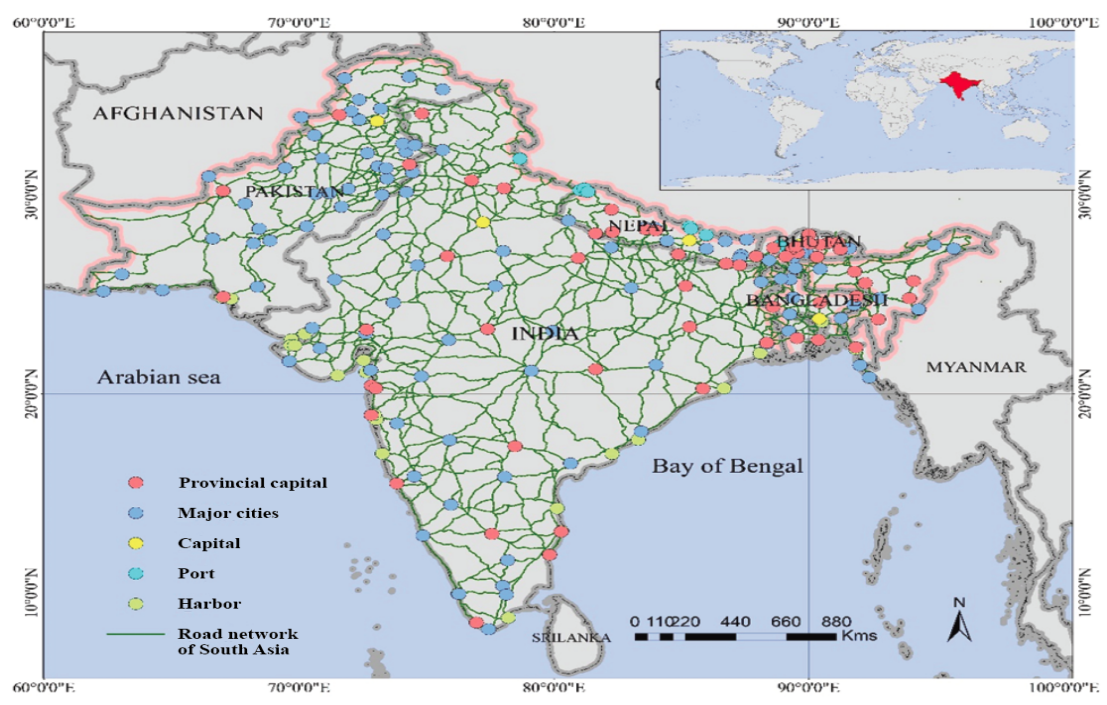

Fig. 3: Finalized node-based road network for South Asia investigated in this study

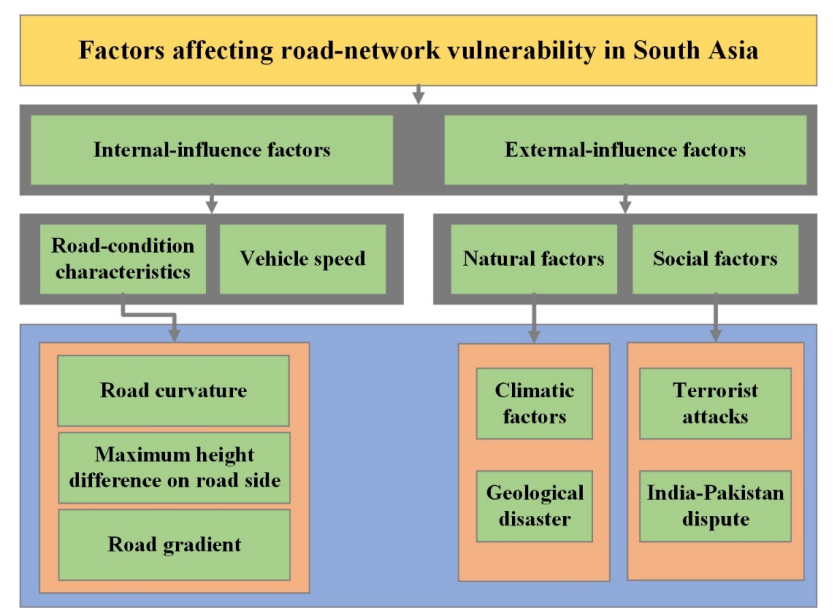

Fig. 4: Indicator system developed for assessing road-network vulnerability in South Asia 


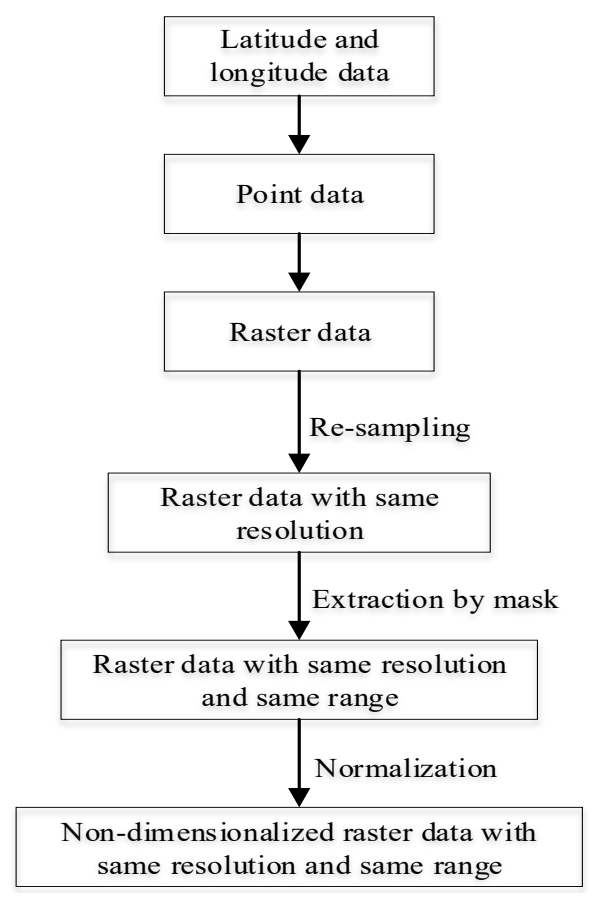

Fig. 5: Flowchart of the raw data preprocessing procedure

\section{Assessment Results}

The transportation vulnerability of road networks in South Asia assessed in this study, in accordance with the above-described AHP-based evaluation method, was categorized into ten levels; each level was assigned a number in the range of $1-10$, thereby representing the degree of vulnerability associated with it. Table 3 lists the specific classification range.

The table indicates that a higher vulnerability level corresponds to a higher probability of loss or degradation of the transportation function concerning a specific road. Assessment results obtained in this study were, therefore, validated in the light of the spatial distribution of traffic-accident statistics and corresponding density analysis obtained from different Indian states during the year 2017. Through the correlation analysis between the accident statistical data and the vulnerability research results, the rationality of the evaluation results is judged according to the fitting effect.

\section{Results of Indicator Quantification}

\section{Assessment of Topographical and Geological Vulnerability}

\section{Topological Vulnerability}

The topographic vulnerability is superimposed with the South Asia road network and the impact map of topographic environmental factors on road network vulnerability is prepared (Fig. 6). It can be seen that the terrain vulnerability distribution has the following characteristics:
(1) As depicted in the top image on the right in Fig. 6, roads subject to major impacts from sloping landscapes are located primarily in north India and the northeast region of Pakistan. This can be attributed to the fact that these regions are located in the Himalayas, which are characterized by a highly undulating terrain. In contrast, most other regions in South Asia exhibit a flat terrain, wherein slopes have a negligible influence on road-network conditions

(2) As depicted in the middle image on the right in Fig. 6, high-curvature areas are primarily located at road junctions and corners and regions demonstrating such high-curvature vulnerability are distributed over the entire network. Therefore, curvature vulnerability can be considered to demonstrate uniform distribution in South Asia. By contrast, a more significant (and dense) distribution of high-curvature vulnerability can be observed in northeast Pakistan and Bangladesh

(3) High vehicle speed, in general, represents higher traffic-bearing capacity of road networks. As depicted in the bottom image on the right in Fig. 6, areas demonstrating high traffic capacity are primarily located in central and south Pakistan as well as the central and western regions of India. In contrast, regions with low traffic capacity are located in northeast Pakistan, Bangladesh and the northeast and southwest regions of India

\section{Geological-Environment Vulnerability}

Spatial-distribution characteristics concerning the seismic vulnerability of South Asian road networks are depicted in Fig. 7. As can be observed, regions subject to a strong impact from seismic vulnerability are mainly located in the northern part of South Asia. In addition, several regions with lower seismic vulnerability also exist in the western part of the subcontinent. In fact, the northern part of South Asia lies at the junction between two tectonic plates. Geological activities in this region are, therefore, particularly strong and this constitutes a major factor contributing to the high vulnerability of road networks in this region.

Table 3: Vulnerability range classification

\begin{tabular}{ll}
\hline Level & Vulnerability range \\
\hline 1 & $0.0000-0.0679$ \\
2 & $0.0679-0.1342$ \\
3 & $0.1342-0.1662$ \\
4 & $0.1662-0.1879$ \\
5 & $0.1879-0.2107$ \\
6 & $0.2107-0.2376$ \\
7 & $0.2376-0.2787$ \\
8 & $0.2787-0.3386$ \\
9 & $0.3386-0.6196$ \\
10 & $0.6196-1.0000$ \\
\hline
\end{tabular}




\section{Assessment of Meteorological-Environment Vulnerability}

\section{Precipitation Vulnerability}

Figure 8 depicts spatial-distribution characteristics concerning the impact of precipitation in the South Asian subcontinent between June and September in 2018. As can be observed, precipitation during monsoons has only a minor impact on road-network conditions in the northwest region of South Asia. However, the long and narrow coastal region in the southwest part of India experiences the most significant impact of precipitation in terms of both intensity and time. The said precipitation impact is most significant during July. In addition, several parts of central and north India become exposed to strong precipitation impact during this period, followed by August and September; precipitation levels are typically low in June. The overall impact of precipitation is relatively weak in the northwest region and demonstrates medium intensity in the central and eastern regions of South Asia. Additionally, a somewhat strong influence of precipitation can be observed in a small region in northeast India, Nepal and Bhutan.

\section{Impact from High Temperature}

Figure 9 depicts the spatial distribution of the impact of high temperature in South Asia during the summer months-March to May. As depicted in the figure, the observed high-temperature impact weakens as one moves away from the central part of India. As can be observed in maps depicted on the right in Fig. 9, as summer progresses from March to May, the region of maximum hightemperature influence moves from the southeast inland of south Asia to the northwest inland. The corresponding impact of high temperature on road-network vulnerability in South Asia has also been summarized in Fig. 9. The extreme north and northeast regions of India (i.e., the Himalayas) experience the least high-temperature impact, whereas the remaining regions within the subcontinent experience nearly the same impact. In particular, temperatures in the central Deccan plateau can reach values of up to $35^{\circ} \mathrm{C}$ while the maximum absolute temperature in the Thar desert may even exceed $50{ }^{\circ} \mathrm{C}$. Consequently, these regions can rightly be classified as high-temperature danger zones.

\section{Assessment of Social-Environment Vulnerability}

\section{Vulnerability Associated with Terror Attacks}

Figure 10 depicts spatial-distribution characteristics concerning the influence of terrorist attacks in South Asia. As depicted in the figure, regions affected by the high intensity of such attacks are mostly concentrated in the northwest part of the subcontinent. In particular, the northeast region of Pakistan experiences the most severe threat from terror attacks and therefore, it demonstrates the highest level of terror-attack vulnerability. It can also be noticed that prominent terror-attack locations are highly concentrated in only a few regions. Apart from these regions wherein such attacks frequently occur, most regions in South Asia are less prone to terrorist activities.

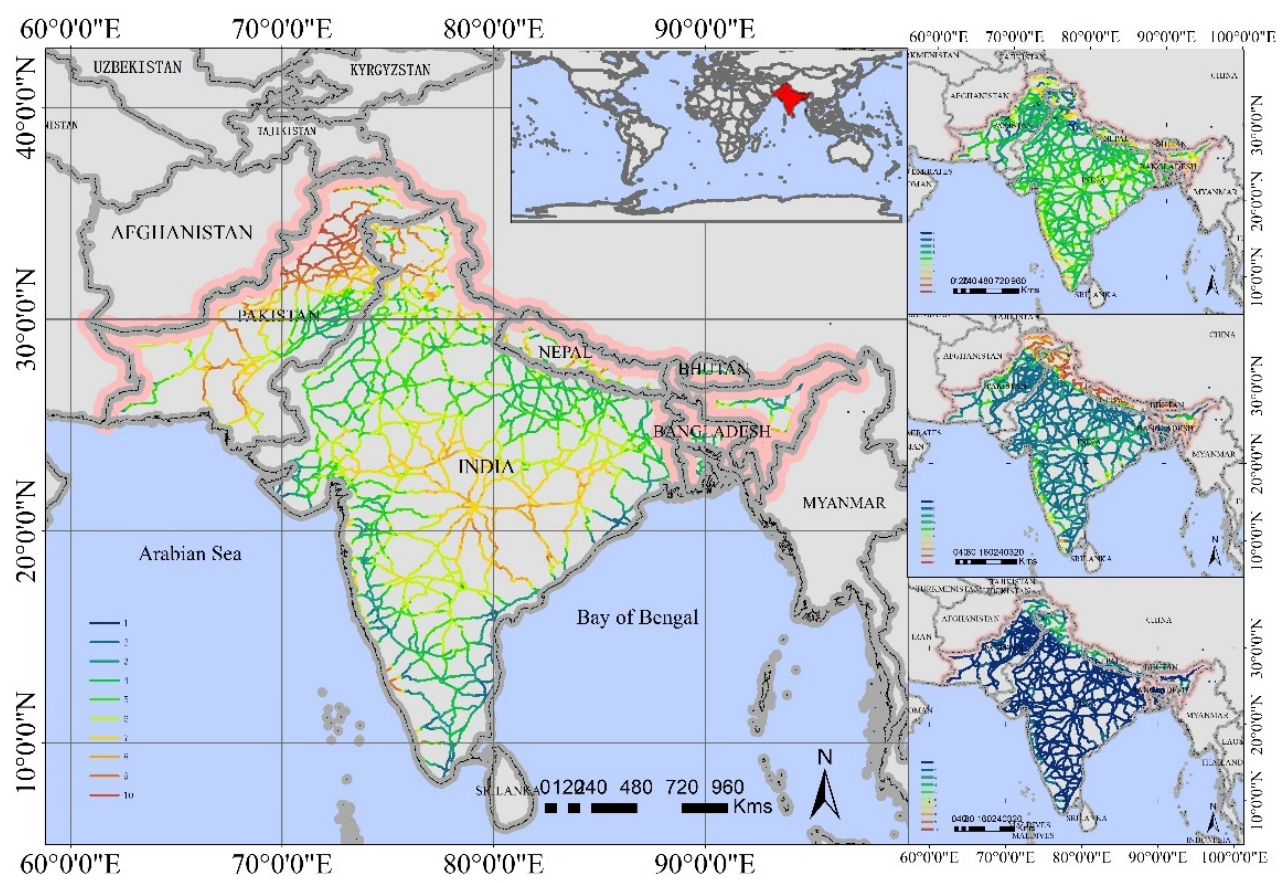

Fig. 6: Comprehensive topographical vulnerability map for South Asian road networks 


\section{Vulnerability Associated with India-Pakistan Conflict}

The India-Pakistan conflict has been caused by territorial disputes between India and Pakistan since their partition in 1947. The repercussions of the conflict are primarily experienced in the form of travel restrictions imposed by the two countries as well as the disruption of the road network connecting them. Road-network vulnerability caused by the India-Pakistan conflict is mainly observed along the border that divides the two nations. To mark the interrupted road network along the India-Pakistan border, a 5-km wide buffer zone was considered in this study using ArcGIS and the same was assigned with a vulnerability level of 10 .

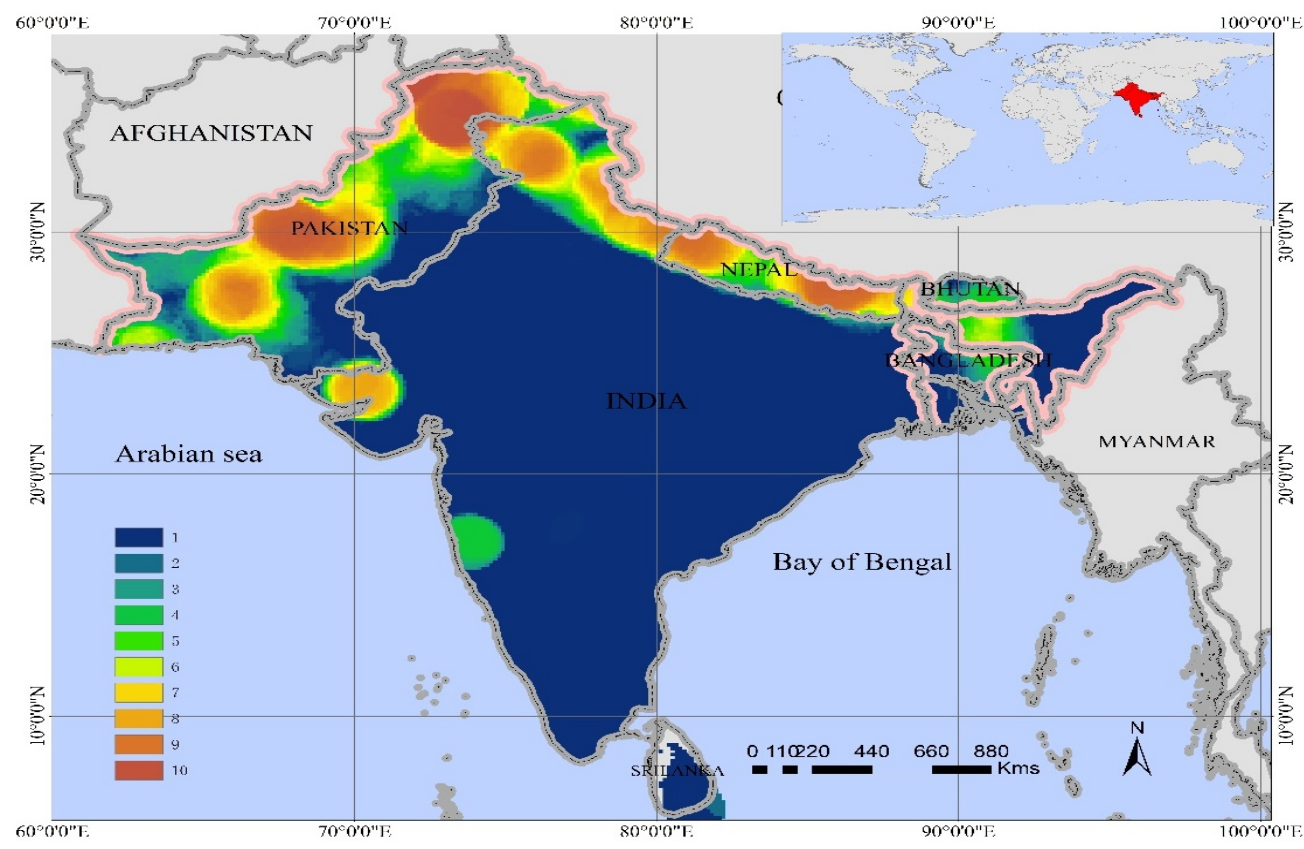

Fig. 7: Spatial distribution of seismic vulnerability in South Asia

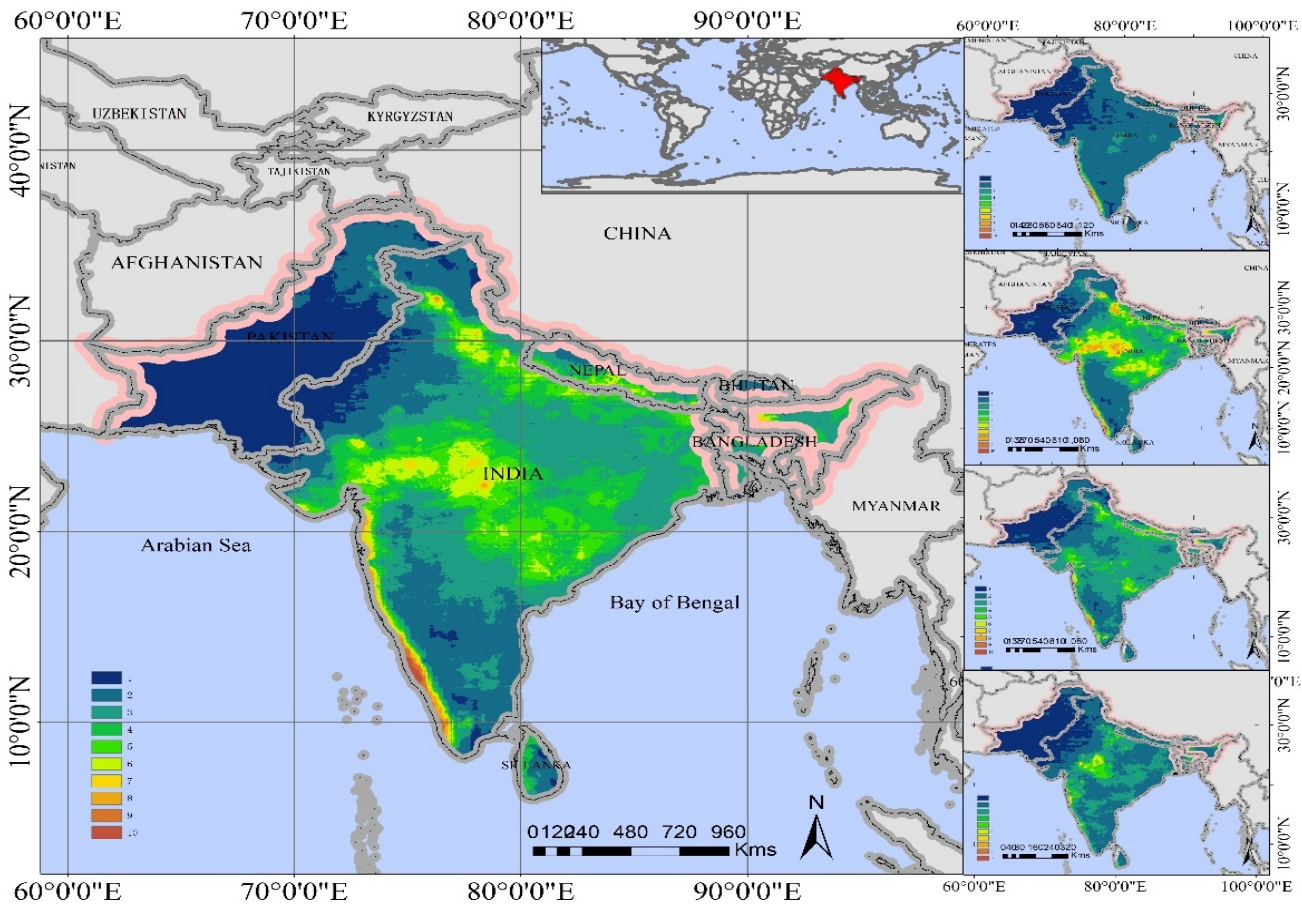

Fig. 8: Impact of precipitation on South Asian subcontinent during monsoons 


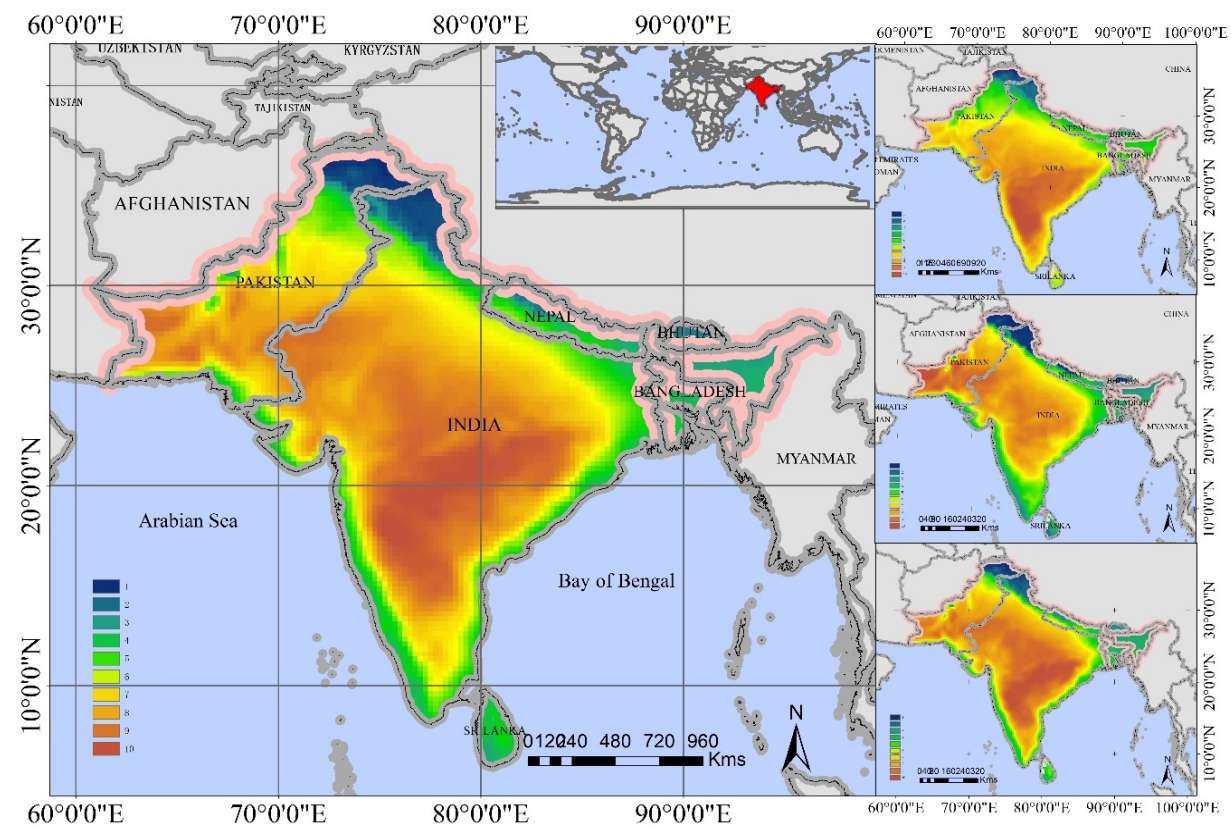

Fig. 9: Distribution of high-temperature vulnerability in South Asia

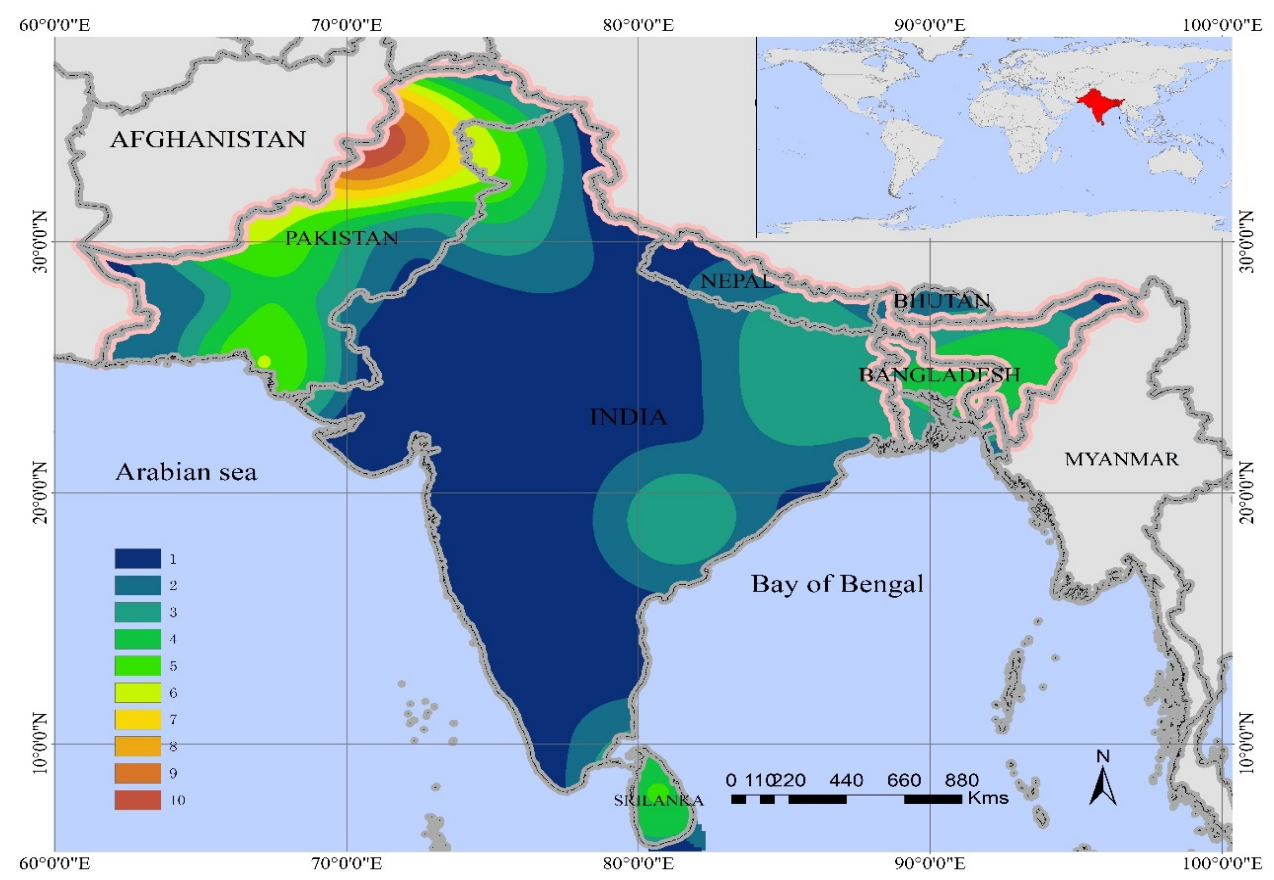

Fig. 10: Spatial distribution of terror-attack vulnerability in South Asia

Overall Assessment Results Concerning RoadNetwork Vulnerability in South Asia

\section{Validation of Assessment Results}

For validating the precision of the obtained assessment results concerning road-network vulnerability in South Asia, traffic-accident statistics and corresponding density analysis (Fig. 11) performed in India during the year 2017 were considered as reference data owing to their easy accessibility. The said data were subsequently compared against vulnerability-assessment results concerning Indian roads (Fig. 12) for performing correlation analysis and evaluating the overall performance of the proposed method. Since the 
exact locations of the occurrence of traffic accidents were not known, the precision analysis was performed using a statelevel spatial scale. This, in turn, resulted in minor deviations being observed in the final results.

Based on above-described results obtained via the vulnerability-assessment of South Asian road networks, regions with high road-network vulnerability in India were observed to be mainly distributed within the northwestern Himalayas, central and northern parts of the Deccan plateau and western coastal areas. Additionally, results obtained via the analysis of traffic-accident density in India indicate regions with high accident density to also be concentrated within the northwestern Himalayas, southwest coastal region and north-central Deccan plateau. The spatial distributions obtained using the two datasets showed good agreement. Further, a correlation analysis was performed concerning the number of traffic accidents occurring in different Indian states and the associated vulnerability value of road networks. As a result of this analysis, a trend line with an $\mathrm{R}^{2}$ value of 0.4369 was obtained, thereby verifying the reasonability of assessment results obtained in this study Fig. 13.

\section{Distribution of Road-Network Vulnerability in South Asia}

Results obtained in this study (as depicted in Fig. 14) via the above-mentioned comprehensive vulnerability assessment of South Asian road networks revealed the following spatial-distribution characteristics.

The distribution of road network vulnerability level in India shows an overall trend of decreasing from the middle to the surrounding and the road network vulnerability in the middle and north of Deccan Plateau is the highest, with a vulnerability of Grade $7 \sim 8$. In addition, road networks along the west coast of India and those in the northern mountainous region overlapping with the southern Himalayas were also identified as being highly vulnerable (vulnerability level: 7-8) owing to the influence of various topographical factors. The said vulnerable road networks were observed to be distributed in the belt pattern in these regions.

In Pakistan, road-network vulnerability was observed to weaken along the north-south direction, despite overall vulnerability levels remaining high throughout the country. Because the northern part of Pakistan is located in the Himalayas, which are characterized by a highly undulating terrain and frequent occurrence of geological and meteorological disasters, the vulnerability of local road networks therein lies in the range of 9-10. Additionally, in view of the India-Pakistan conflict, road networks along the India-Pakistan border exhibit the highest vulnerability and these have, therefore, been characterized as belonging to the peak vulnerability zone in South Asia.

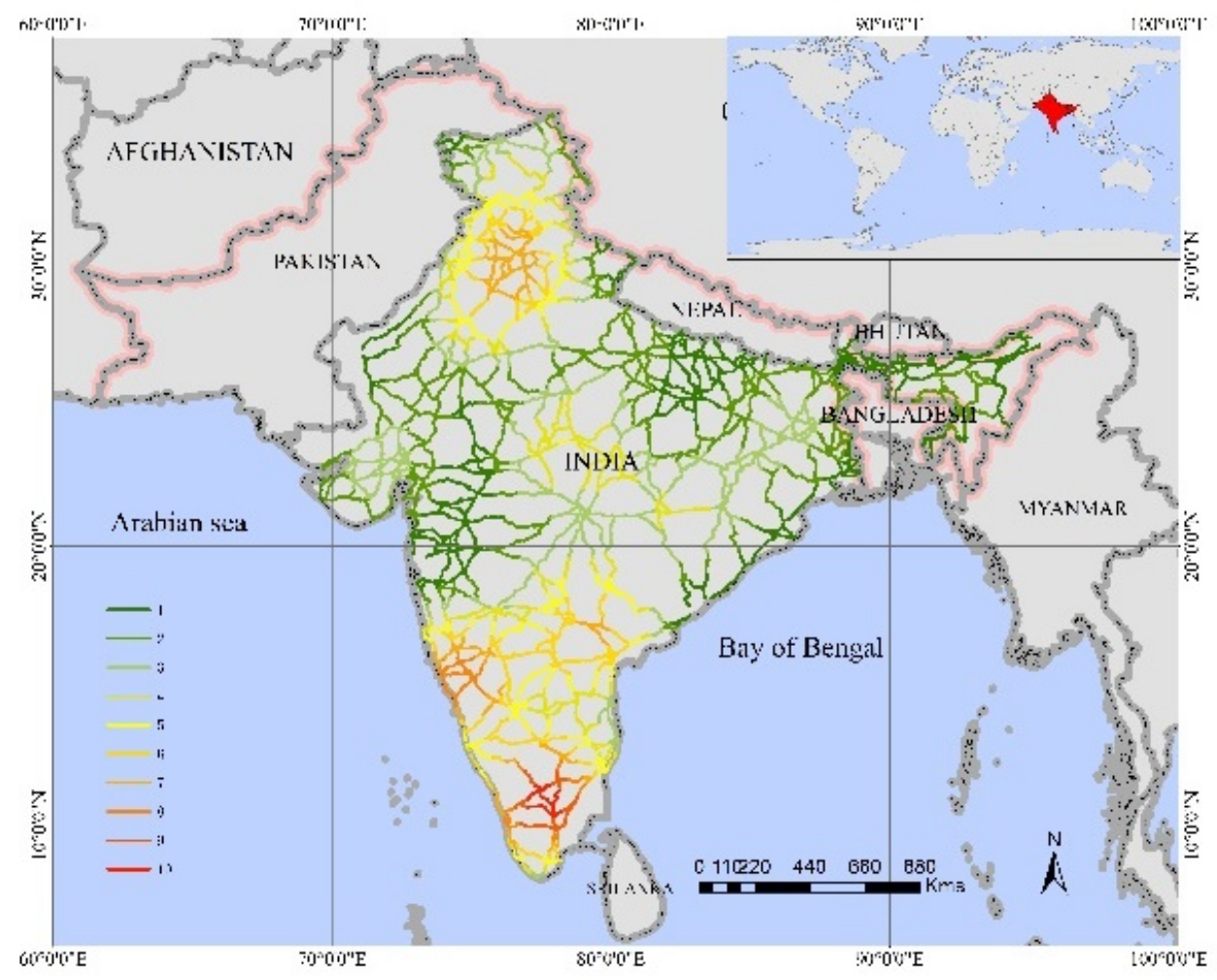

Fig. 11: Results obtained via statistical analysis of traffic accidents in India and their corresponding density 


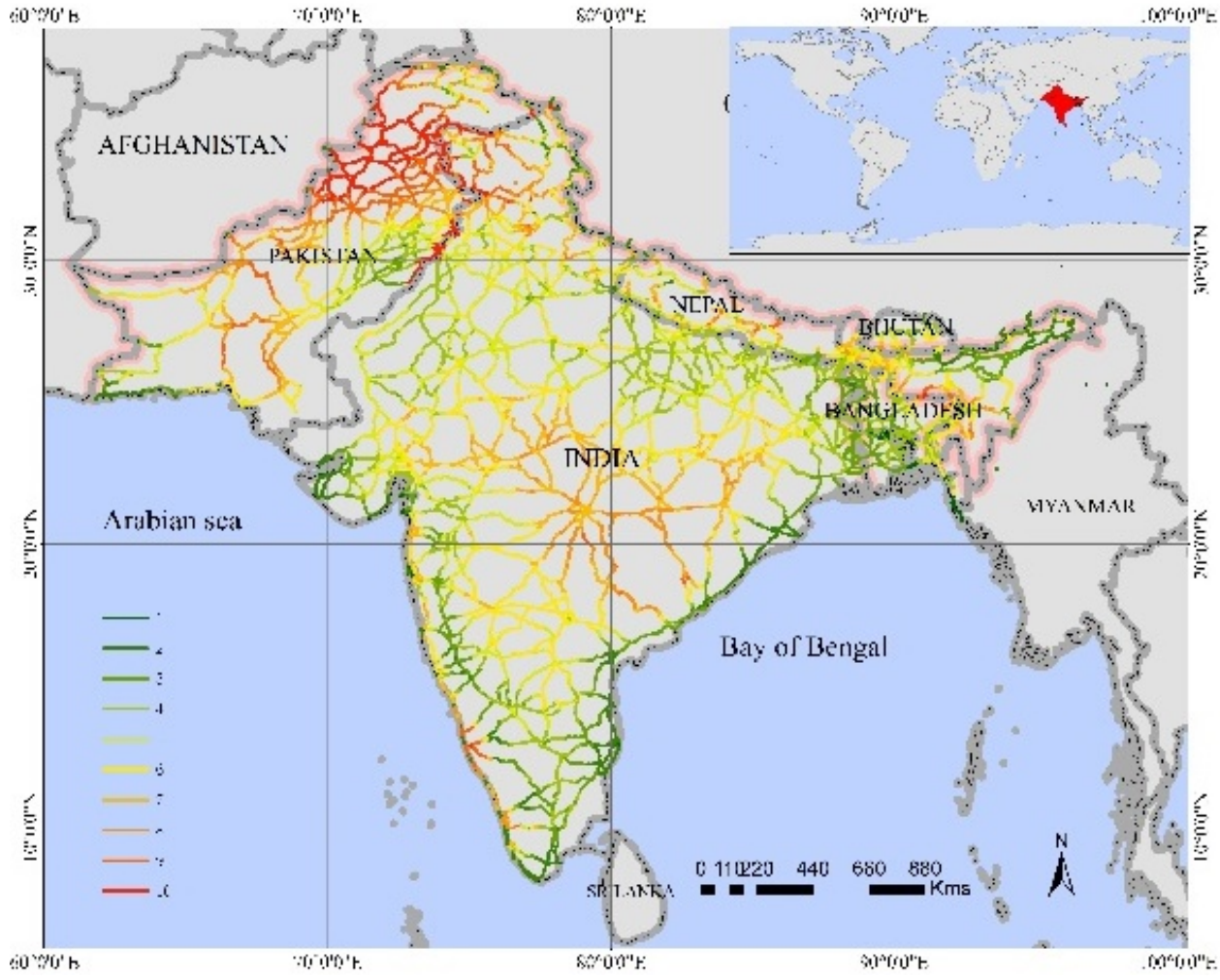

Fig. 12: Vulnerability-analysis results for South Asian road networks

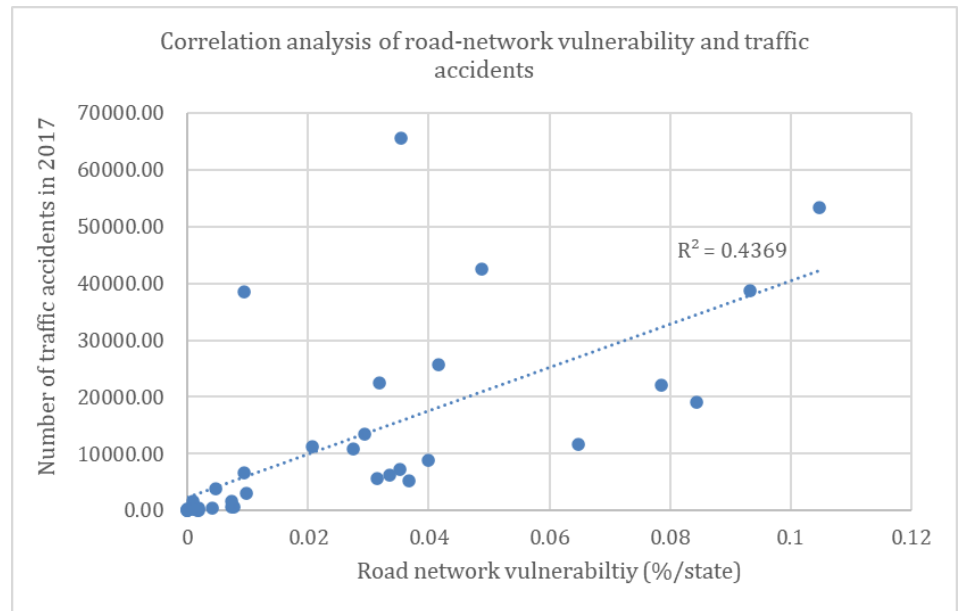

Fig. 13: Correlation analysis of road-network vulnerability and traffic accidents (equation of fitting curve: $y=380010 x+2436.1$ )

By performing a statistical analysis of road lengths assigned with different vulnerability levels, it was observed that the total length of roads assigned with vulnerability levels 4 and 5 is significantly greater than that of roads assigned with other vulnerability levels in South Asia. As depicted in Fig. 15, the plot of the relative lengths of roads in South Asian countries follows the normal distribution with respect to their corresponding level of vulnerability assigned. As can be observed, the total length of roads with extremely high and low vulnerability levels is substantially smaller compared to that of roads assigned with levels 4 and 5. The overall vulnerability level of road networks within the entire subcontinent can be observed to be concentrated near medium to low values. This result implies that South Asian road networks possess a strong capability to sustain normal traffic flow. In other words, road networks within the South Asian subcontinent are relatively stable. 


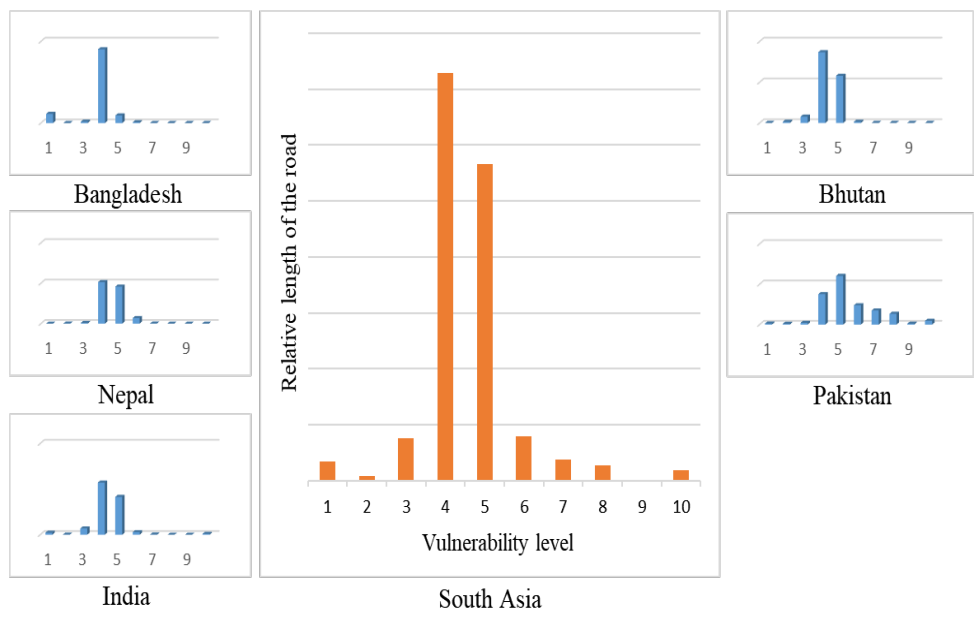

Fig. 14: Distribution of relative road length corresponding to different vulnerability levels in South Asia. (Note: As this study was limited to potential vulnerability of the land transport network, sea traffic was excluded; thus, Sri Lanka and the Maldives were not considered.)

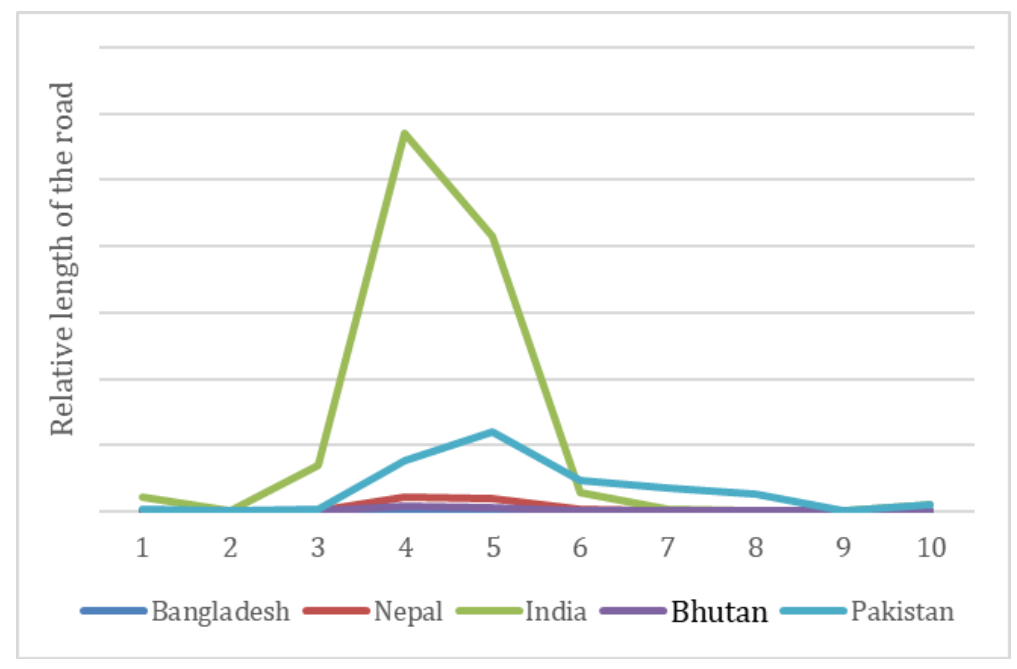

Fig. 15: Trend of relative road length associated with different vulnerability levels for different countries

Figure 15 also demonstrates that the road-network vulnerability within each South Asian country follows a normal distribution pattern nearly identical to that observed for the entire subcontinent. The vulnerability of road networks in Bangladesh is mainly concentrated around level 4, smaller compared to the corresponding average for South Asia. Vulnerability levels for India, Bhutan and Nepal were, similarly, concentrated around levels 4 and 5, thereby demonstrating consistency with the overall behavior of the subcontinent. The average vulnerability level of road networks in Pakistan approximately equaled 5 owing to the existence of several highly vulnerable roads. In addition, the total length of roads with vulnerability levels $6,7,8$ and even 10 is significantly greater in Pakistan compared to the rest of the subcontinent. Therefore, the overall stability of road networks in Pakistan is relatively poor. Comparing the relative-road-length distribution associated with each vulnerability level for all countries (Fig. 15), it can be inferred that road networks in Bangladesh exhibit the lowest level of vulnerability closely followed by those in India, Bhutan and Nepal, in that order. Lastly, road networks in Pakistan exhibit the highest level of vulnerability.

\section{Discussion}

This study discussed the comprehensive evaluation methods for road network vulnerability based on the unique geographical characteristics of South Asia. The results indicated that certain extreme natural and social factors (including high temperature and terrorist attacks) pose a significant impact on the service capacity of road networks 
and as such have become the determinants of road network vulnerability. The concept definition and comprehensive evaluation method for road network vulnerability proposed in this study have demonstrated proven values.

The study has shown that analyzing the consequences of a particular road blockage can help identify important road sections that will severely influence the entire road network if damaged. An important road section may not necessarily be vulnerable; however, the high damage probability of the road sections of less importance introduces a larger potential vulnerability to the network. Therefore, we define the vulnerability of the road network as its potential damage probability, that is, the vulnerability of the road network is equivalent to its sensitivity to a series of social and natural events that can substantially reduce the service capacity of the road network, where the service capacity describes the possibility of road connection and road accessibility in a given period of time (Berdica and Mattsson 2007).

Road constructions must fully consider social (such as economic development and religious conflicts) and natural (such as geological activities and topography) factors. As the constructed road network is exposed to the natural and social environment, its vulnerability will inevitably be influenced. The evaluation indicators for road network vulnerability can be divided into three categories: Those based on network topology, network operational performance, or travel demand. Quium and Hoque (2002) evaluated the road network connectivity using $\gamma$ and $\alpha$ indicators based on topology. D'Este (2001) instead evaluated the road network accessibility adopting the generalized travel cost based on operational performance. Alternatively, using the road network robustness indicator NRI as a systematic measure, Scott et al. (2006) evaluated the accessibility of the road network from a travel time perspective. Lastly, Nicholson and Dalziell (2003) assessed the accessibility of a road network based on the influences of travel demand and supply changes. However, network structure, operational performance, or travel demand alone cannot fully reflect the actual situation, which requires a more exhaustive indicator. Therefore, we analyzed nine types of social and natural indicators that can potentially influence the road network vulnerability, including road curvature, maximum height difference of two sides of the road, road gradient, road traffic speed, rainfall, earthquake, high temperature, terrorist attack and Indo-Pakistani conflict. In addition, each indicator was quantified individually combining its action mode and intensity on the road network, thus providing a comprehensive evaluation of the road network vulnerability. The proposed method can clearly identify the leading factor of the high-vulnerability area of the road network, facilitating management adapted to local conditions.
The evaluation model for road network vulnerability should be established on a rational analysis, scientific quantification and accurate spatial location, all of which are indispensable. Earlier, transport reliability studies introduced travel time reliability, terminal (connectivity) reliability and capacity reliability as the main performance measures for road networks (Berdica and Mattsson, 2007). However, owing to differences in the road network environments in various regions, a unified indicator system and evaluation criteria for road network vulnerability is lacking. Bell et al. (2008) utilized link characteristics such as permitted speeds, capacities and the number of lanes to establish a model for the entire Greater London road network. In this study, by taking into full consideration the geographical uniqueness of South Asia and combining with the road network environment of the region, multiple indicators were selected, the weights of which were determined by an analytic hierarchy process. To improve the rationality of the model, in addition to qualification, a reasonable quantitative calculation of each indicator was performed by considering the action mode and intensity of the indicator on the road network. For example, the number of deaths was adopted to represent the impact of a terrorist attack. This quantitative calculation of the contribution of a single indicator to the overall vulnerability resolved the issue of subjectivity during the indicator system construction to some extent. The distribution of the road network vulnerability is spatially continuous; therefore, by spatially plotting the vulnerability onto the road network using the GIS technology, the distribution trend and the intensity of the road network vulnerability in South Asia can be visualized, which is more straightforward than only digital analysis.

Road traffic injuries are the ninth leading cause of death in the world, resulting in $1.3 \mathrm{~m}$ letters will appear and between 20 and $50 \mathrm{~m}$ letters nonfatal injuries each year (Sleet et al., 2011). Evaluating network infrastructures for potential vulnerabilities is an important component of strategic planning, particularly in the context of managing and mitigating service disruptions (Murray et al., 2008). Measures to assess the vulnerability quantitatively can be used as guidance to road administrations for prioritizing the maintenance and repair of roads, as well as for avoiding causing unnecessary disturbances in the planning of roadwork (Jenelius and Mattsson, 2012). Based on the complicated coupling relationship between the regional vulnerable sources and the road network vulnerability, the study has selected scientific evaluation indicators for analysis and quantification and it has established an evaluation model and performed spatial location for road network vulnerability. Therefore, the vulnerable sections in the South Asia road network can be spotted, thereby facilitating road administrators to plan and manage regional traffic, avoid areas where high-vulnerability road networks are distributed and rationally design road networks. 
Targeting the road network systems of specific South Asian countries, the model established in this study has fully considered the unique natural and social conditions of South Asia. However, as the influencing factors of the road networks around the world share common features, the concept and method described in this study can be applied more extensively. Its implementation in road networks with larger ranges and more complicated influencing factors can be realized by adjusting model indicators as well as quantification and weighting methods according to factors such as the range, frequency and intensity of the indicators in different regions.

Although this study has integrated natural and social environmental factors to analyze road network vulnerability, which provides a valuable reference for similar works in the future, further investigation is required on the rationale quantification of indicators to accurately reflect their ability to damage roads or to reduce the service capacity of road networks.

\section{Conclusion}

This study proposed a comprehensive evaluation model for regional road network vulnerability that considers the geographical uniqueness of South Asia based on a mathematical modelling method. The model combined qualitative, quantitative and localization analysis techniques and simultaneously considered both natural and social factors; this makes it a comprehensive evaluation method that has multiple integrated factors. The model was subsequently utilized to evaluate the spatial distribution characteristics of road network vulnerability in South Asia, thereby facilitating the administration of regional traffic. The results show that.

From the perspective of individual elements, roads subject to major impacts from sloping landscapes are located primarily in north India and the northeast region of Pakistan; high-curvature areas are primarily located at road junctions and corners, by contrast, a more significant (and dense) distribution of high-curvature vulnerability can be observed in northeast Pakistan and Bangladesh; areas demonstrating high traffic capacity are primarily located in central and south Pakistan as well as the central and western regions of India. In contrast, regions with low traffic capacity are located in northeast Pakistan, Bangladesh and the northeast and southwest regions of India; regions subject to a strong impact from seismic vulnerability are mainly located in the northern part of South Asia. In addition, several regions with lower seismic vulnerability also exist in the western part of the subcontinent; the overall impact of precipitation is relatively weak in the northwest region and demonstrates medium intensity in the central and eastern regions of South Asia. Additionally, a somewhat strong influence of precipitation can be observed in a small region in northeast India, Nepal and Bhutan; the extreme north and northeast regions of India (i.e., the Himalayas) experience the least high-temperature impact, whereas the remaining regions within the subcontinent experience nearly the same impact; regions affected by the high intensity of terrorist attacks are mostly concentrated in the northwest part of the subcontinent. In particular, the northeast region of Pakistan experiences the most severe threat from terror attacks; road-network vulnerability caused by the IndiaPakistan conflict is mainly observed along the border that divides the two nations.

From the national scale, the distribution of road network vulnerability levels in various countries is consistent with that in South Asia, with a roughly normal distribution. Among them, the overall vulnerability level of road network in Bangladesh is lower than that in South Asia; The distribution of road network vulnerability in India, Bhutan and Nepal is consistent with that in South Asia; There are many sections with high vulnerability in Pakistan, the relative length of sections with high vulnerability is significantly higher than the overall level and the overall road network stability in Pakistan is poor. In terms of the proportion of relative length distribution of road sections at each vulnerability level, the road network vulnerability of Bangladesh is the lowest, followed by India and Bhutan, followed by Nepal and the road network vulnerability of Pakistan is the highest.

In addition, the vulnerability distribution of road network in South Asia shows an overall trend of decreasing from the middle to the surrounding areas, the high-vulnerability areas of road network are concentrated in northern Pakistan, the Deccan Plateau, the western coastal areas of India and the foothills of the Himalayas. Among these areas, the road networks in the foothills of the Himalayas and northern Pakistan are affected by topographical and geological factors as well as terrorist attacks, whereas those in the Deccan Plateau and the western coastal areas of India are affected by meteorological factors.

The analysis of the distribution of road network vulnerability indicated that the South Asian road network is generally in a stable state. The road network vulnerability is predominantly distributed in the middle and low levels and the road network has highly reliable accessibility. The transportation system in South Asia relies heavily on road transportation, which provides inherent advantages over the other two transportation modes: Railway and waterway.

The study results suggest that road planning in South Asia should focus on the potential high-vulnerability areas in the road network. Infrastructure constructions should be improved and the strength and service capacity of the road networks should be enhanced to achieve accurate warning of traffic accidents, rational design of road networks and prompt response to emergencies. The results and method of this study can provide scientific and methodological references for road network vulnerability evaluation in other regional networks. 


\section{Acknowledgement}

This work was supported by the National Key Research and Development Plan (Grant No. 2017YFB0504205) and National Natural Science Foundation of China (41801298).

\section{Author's Contributions}

Pan Yuqi: Conceptualization, writing-original draft, methodology, formal analysis, writing-and editing.

Jiang Penghui: Methodology, resources, writingreviewing and editing, funding acquisition.

Li Manchun: Conceptualization, resources, supervision, funding acquisition.

Chen Dengshuai: Methodology, writing-reviewing and editing, investigation, validation.

\section{Ethic}

This article is original and contains unpublished material. The corresponding author confirms that all of the other authors have read and approved the manuscript and no ethical issues involved.

\section{References}

Bell, M. G., Kanturska, U., Schmöcker, J. D., \& Fonzone, A. (2008). Attacker-defender models and road network vulnerability. Philosophical Transactions of the Royal Society A: Mathematical, Physical and Engineering Sciences, 366(1872), 1893-1906. doi.org/10.1098/rsta.2008.0019

Berdica, K., \& Mattsson, L. G. (2007). Vulnerability: A model-based case study of the road network in Stockholm. In Critical infrastructure (pp. 81-106). Springer, Berlin, Heidelberg.

https://link.springer.com/chapter/10.1007/978-3540-68056-7_5

Chen, B. Y., Lam, W. H., Sumalee, A., Li, Q., \& Li, Z. C. (2012). Vulnerability analysis for large-scale and congested road networks with demand uncertainty. Transportation Research Part A: Policy and Practice, 46(3), 501-516. doi.org/10.1016/j.tra.2011.11.018

D'ESTE, G. M. (2001). Modelling network vulnerability at the level of the national strategic transport network. Journal of the Eastern Asia Society for transportation studies, 4(2), 1-14. https://ci.nii.ac.jp/naid/10030113299/

Gedik, R., Medal, H., Rainwater, C., Pohl, E. A., \& Mason, S. J. (2014). Vulnerability assessment and re-routing of freight trains under disruptions: A coal supply chain network application. Transportation Research Part E: Logistics and Transportation Review, 71, 45-57. doi.org/10.1016/j.tre.2014.06.017
Grubesic, T. H., Matisziw, T. C., Murray, A. T., \& Snediker, D. (2008). Comparative approaches for assessing network vulnerability. International Regional Science Review, 31(1), 88-112. doi.org/10.1177/0160017607308679

Jenelius, E., \& Mattsson, L. G. (2012). Road network vulnerability analysis of area-covering disruptions: A grid-based approach with case study. Transportation research part A: Policy and practice, 46(5), 746-760. doi.org/10.1016/j.tra.2012.02.003

Kermanshah, A., \& Derrible, S. (2016). A geographical and multi-criteria vulnerability assessment of transportation networks against extreme earthquakes. Reliability Engineering \& System Safety, 153, 39-49. doi.org/10.1016/j.ress.2016.04.007

Kim, S., \& Yeo, H. (2016). A flow-based vulnerability measure for the resilience of urban road network. Procedia-Social and Behavioral Sciences, 218, 1323. doi.org/10.1016/j.sbspro.2016.04.006

Liu, J., Shi, Z., \& Tan, X. (2021). Measuring the dynamic evolution of road network vulnerability to floods: a case study of Wuhan, China. Travel behaviour and society, 23, 13-24. doi.org/10.1016/j.tbs.2020.10.009

Lu, Q. C., Xu, P. C., \& Zhang, J. (2021). Infrastructurebased transportation network vulnerability modeling and analysis. Physica A: Statistical Mechanics and its Applications, 584, 126350. doi.org/10.1016/j.physa.2021.126350

Miller, H. J., Cutter, S. L., Richardson, D. B., \& Wilbanks, T. (2003). 5.3 Transportation and Communication Lifeline Disruption.

https://citeseerx.ist.psu.edu/viewdoc/download?doi= 10.1.1.15.1935\&rep=rep1\&type $=$ pdf

Murray, A. T., Matisziw, T. C., \& Grubesic, T. H. (2008). A methodological overview of network vulnerability analysis. Growth and Change, 39(4), 573-592. doi.org/10.1111/j.1468-2257.2008.00447.x

Quium, A. S. M. A., \& Hoque, S. A. M. A. (2002). The completeness and vulnerability of road network in Bangladesh. Engineering concerns of flood, 59-75. https://salekseraj.com/Page59-Abdul-Quium.pdf

Reggiani, A., Nijkamp, P., \& Lanzi, D. (2015). Transport resilience and vulnerability: The role of connectivity. Transportation research part A: Policy and practice, 81, 4-15. doi.org/10.1016/j.tra.2014.12.012

Scott, D. M., Novak, D. C., Aultman-Hall, L., \& Guo, F. (2006). Network robustness index: A new method for identifying critical links and evaluating the performance of transportation networks. Journal of Transport Geography, 14(3), 215-227. doi.org/10.1016/j.jtrangeo.2005.10.003

Singh, P., Sinha, V. S. P., Vijhani, A., \& Pahuja, N. (2018). Vulnerability assessment of urban road network from urban flood. International journal of disaster risk reduction, 28, 237-250. doi.org/10.1016/j.ijdrr.2018.03.017 
Sleet, D. A., Baldwin, G., Dellinger, A., \& Dinh-Zarr, B. (2011). The decade of action for global road safety. Journal of safety research, 42(2), 147-148. doi.org/10.1016/j.jsr.2011.02.001

Soehodho, S. (2017). Public transportation development and traffic accident prevention in Indonesia. IATSS research, 40(2), 76-80.

doi.org/10.1016/j.iatssr.2016.05.001

Sohn, J. (2006). Evaluating the significance of highway network links under the flood damage: An accessibility approach. Transportation research part A: policy and practice, 40(6), 491-506. doi.org/10.1016/j.tra.2005.08.006
Tang, Y., \& Huang, S. (2019). Assessing seismic vulnerability of urban road networks by a Bayesian network approach. Transportation research part D: Transport and environment, 77, 390-402. doi.org/10.1016/j.trd.2019.02.003

Wang, M., Chen, Z., Mu, L., \& Zhang, X. (2020). Road network structure and ride-sharing accessibility: A network science perspective. Computers, environment and urban systems, 80, 101430. doi.org/10.1016/j.compenvurbsys.2019.101430

Wegman, F. (2017). The future of road safety: A worldwide perspective. IATSS research, 40(2), 66-71. doi.org/10.1016/j.iatssr.2016.05.003 